Paper No: SCARA-1.10-01, (50)

\title{
Study of the Effect of Risk Management Application on the Performance of Giad industrial Group
}

\author{
YASSIN ASSADIG ALI AHMED1 \\ *Advanced Industrial Group-Transformative Industries Complex, Khartoum, Sudan \\ yassadig@gmail.com
}

\begin{abstract}
The risk management is particularly important at the present time and constitute a new approach in firms, has seen all industries acceleration and great changes in recent years, in order to benefit from risk management to provide protection for firms and continuity performance its activities should provide the critical success factors for risk management. The research problem is represented in the role of risk management on the performance of industrial firms in Sudan, the research aims to deepen the understanding of risk management and its application to firms and to know the reasons that led to the failure and faltering of the performance of these firms as well as finding appropriate solutions, The researcher used the descriptive analytical method in conducting this study and designed a questionnaire as the main tool for data collection, This research develops through the assumption that there is a positive relationship between risk management and the performance of the firm where the study found that risk management practices are applied in moderate proportions by the leaders and employees of the Sudanese industrial firms and dominated by the reactive method rather than proactive, One of the most important recommendations of the study is that industrial organizations have to adopt effective systems for managing organizational risks and that they be monitored and reviewed for deviations in order to be in line with the strategy of the firm.
\end{abstract}

Key words-Risk Management; Industrial Firms; Performance

\section{INTRODUCTION}

Although chemical industries have produced lots of beneficial products to the mankind in order to sustain life, some of the chemical substances can cause serious pollution as well as hazardous to human. Besides that, the production of some chemical substances is highly flammable and can cause catastrophic incident [1]. This study makes business management practices important through the development of a framework that shows how to align business risk management with performance. Research project has assessed the influence of risk management methods on the performance of an industrial firms; the theory of risk management process has been compared to the actual methods in practice in order to investigate similarities and differences. In other words, the main idea is to see if the said firms are working with risk management approaches and if its use influences the performance of a firm and achieving company strategy.

The origin of the word risk can be found in the twelfth century and is thought to be from either the Arabic word risq or the Latin word risicum Risq might appear to relate to "chance outcomes in general and have neither positive nor negative implication". Therefore, taking a risk can also result in a positive outcome. Risque has mainly negative connotations but the circumstances can be positive. Therefore, in common English usage, the word risk commonly refers to a negative event [2].

\section{A. Problem Statement}

The problem of research is to identify the role of risk management on Sudanese Industrial Firms Performance, ap- plication in the Giad Chemical Group; therefore, the research attempts to answer the following questions:

1) What is risk management? And what dimensions use to measure risk management?

2) What does firm performance mean in Giad chemical group?

3) What the relationship between Risk management which dimensions (strategic risk,operational risk, change risk and control risks) and Industrial Firms performance in Giad chemical group.

This study is going to cover the above mentioned knowledge gap, which is to investigates the role of risk management on firms performance, the effect of such alignment on the firm strategy and the likelihood of success, The findings of this research will help to develop firms risk management skills with organizational culture to firms success and achieving company strategy.

\section{B. Research Objectives}

The main objective of this study was to establish the relationship between firm management risk and firms performance of industrial sector in Sudan, (application on Giad Chemical Group).

\section{Research Hypothesis}

1) Main Hypothey: H1: There is statistically significance relationship between risk management which dimensions (strategic risk, operational risk, change risk and control risks) and industrial firms performance which dimensions (customers 


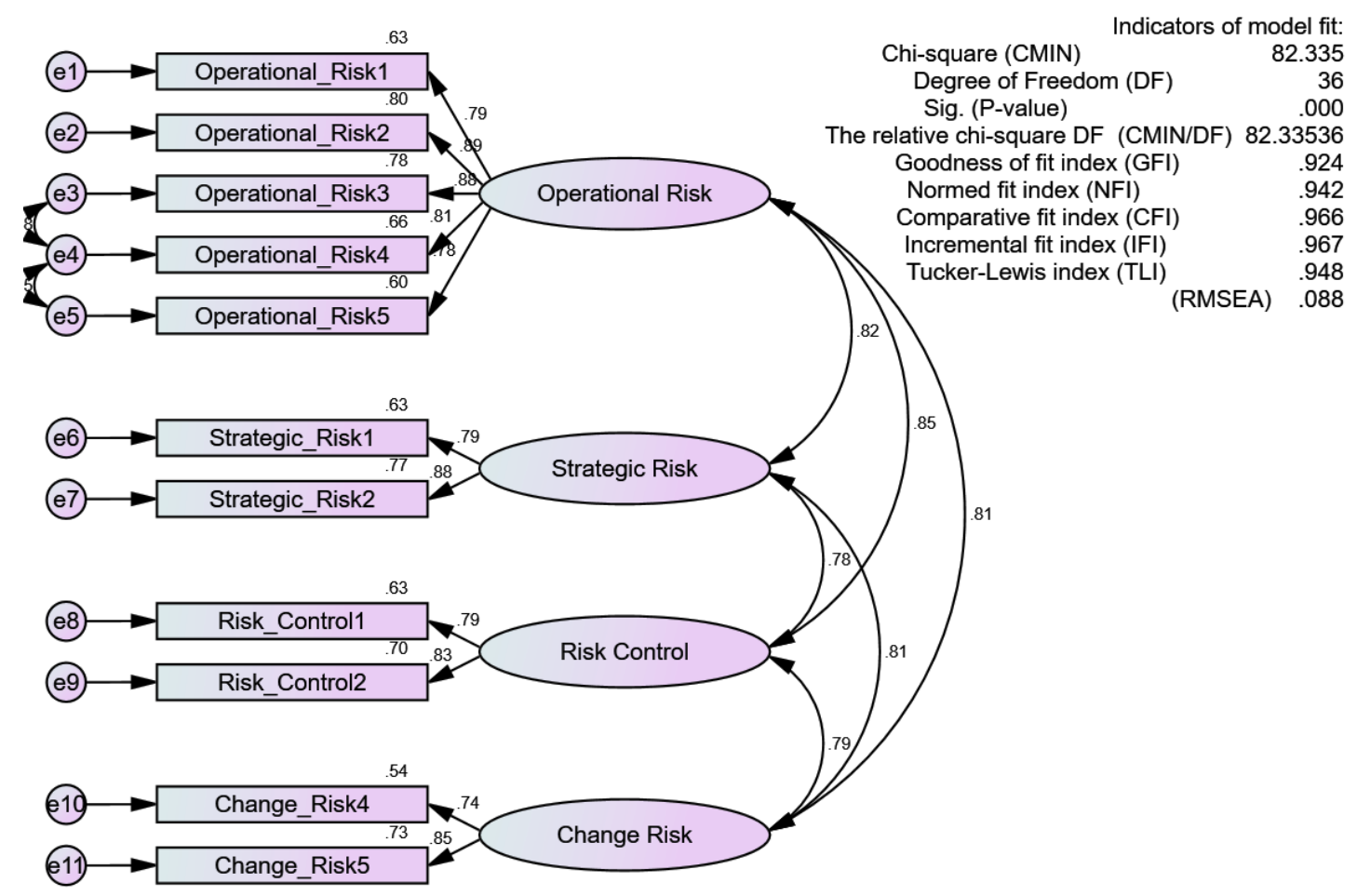

Fig. 1. Model for Risk Management.

satisfaction, employee satisfaction, job performance, and social performance).

2) Sub Hypothesis: H1. There is statistically significant relationship between risk management (multi-dimensional) and customer Satisfaction. H2. There is statistically significant relationship between risk management (multi-dimensional) and employees Satisfaction. H3. There is statistically significant relationship between risk management (multi-dimensional) and job result. H4. There is statistically significant relationship between risk management (multi-dimensional) and social result.

\section{LiteratURE REVIEW}

\section{A. Chemical Industry Definition}

Given its essential role in other sectors, it is not surprising that the chemical sector is a vast and complex industry. Businesses that produce chemicals are closely linked as suppliers and consumers, and depend on other industries, as well as global economic trends [2].

The major raw materials of the chemical industry are fossil fuels, water, air, salt, limestone, sulphur and other specialized raw materials. Industry converts these materials into products; a key feature of the industry is that its products almost always require additional treatment before reaching end users [3].

\section{B. Risk Management}

The Royal Society defined risk as the likelihood of a specific adverse event occurring over a given period of time. Mr. Akintoye stressed this definition because the likelihood of harm and the duration of exposure were included in his study. The source of the risk cannot sometimes be identified, the source is limited knowledge of employees and managers, limited experience and the cause of the information causing the risk. The source of the risk may be changes in the parties included in construction process. Sometimes the risk come from financial markets, project failures, legal liabilities, credit risk, accidents, natural causes and disasters and from competitors [3].

\section{Risk Management Definition}

Risk management has a different definition which is based on both its origin and practice. The practice of risk management began in ancient times, in the earliest period of human existence, and during everyday life our human nature exploits our experiences and uses our instinct to survive. In 1998, a letter from Douglas Barlow, a risk manager of Canadas Massey Ferguson Company, to the author gave genetic expression to this, which reiterates this sentiment that risk management is innate [1]. The royal society had defined the risk as the probability that a particular adverse event occurs during a stated period of time [4].

Risk management is a systematic process of identifying, assessing and responding to project risk. The overall goal of the risk management process is to maximize the opportunities and minimize the consequences of a risk event [5].

In any industry risk management studies, risk identification is the foremost and indispensable stage in risk management. Without risks being identified appropriately, management strategies and measures may be ineffective in spite of the money and efforts expended. Risk identification stage, 


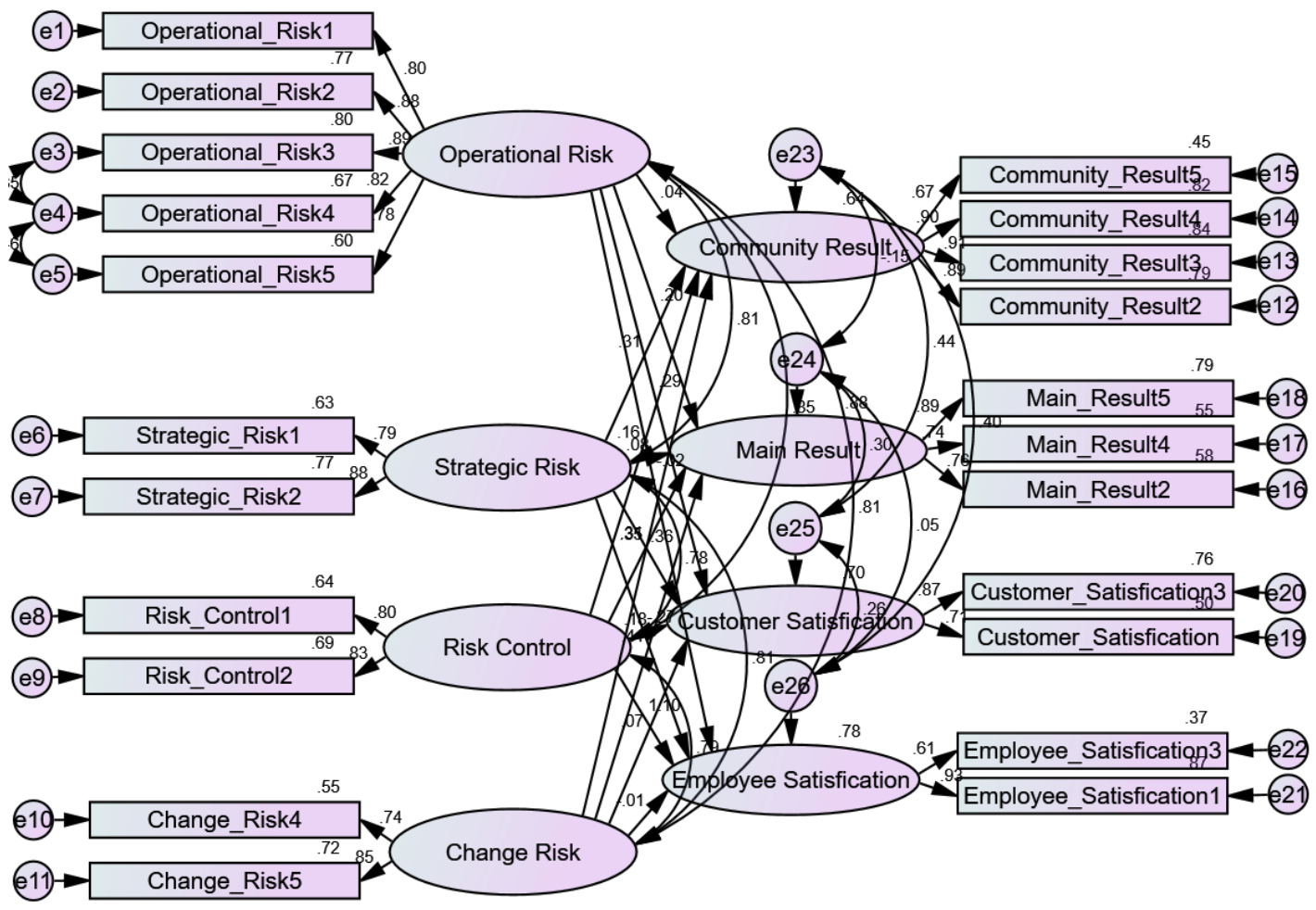

Fig. 2. Structural Model Estimation for Risk Management and Firm Performance.

however, does not end simply by creating a lengthy list of risks and/or risk events, but requires a classification of those risks because the list has some drawbacks [6].

Risk analysis is the second stage in risk management process (RMP) where collected data about the potential risk are analyzed. Risk analysis can be described as short listing risks with the highest impact on the firm, out of all threats mentioned in the identification phase. Although some researchers distinguish between terms risk assessment and risk analysis and describe them as two separate processes [7].

\section{Chemical Industrial Group}

Giad industrial group was established in 1993 and was inaugurated in 2000, with the vision of being the largest industrial group in Africa, according to the mission of leading the industrial, agricultural and developmental renaissance and being one of the pioneers of industry in the region and one of the biggest pillars of the national economy. The Chemical Industries Group is branch of Giad Industrial Group, $50 \mathrm{~km}$ southeast of Khartoum.

\section{E. Fields of work}

Chemicals, alkali materials such as caustic soda, inputs for paints, inputs of mining operation, Urea fertilizer (project) and other industries.

\section{Methodology}

The unit of analysis is the firm; the research design followed the design process suggested by Saunders et al. [4] a deductive approach was chosen, testing hypotheses with data collected through a questionnaire. The survey-based research was selected for investigating the importance of the key factors extracted from the literature reviews based on firm managers' lens; survey research fits the cases in which the researcher wishes to answer questions regarding the distribution of the variables or the relationships among characteristics of people or groups, allowing generalization for a broader population.

\section{A. Target Respondents}

As this research aims to find the role of risk management on Firm performance in Giad Chemical Group - Sudan, it is necessary to get a response from the person who is in a position to understand the overall process of risk management within a firm. The Chemical Industries Group contains three companies with a total of 425 employees. Accordingly, the researcher will distribute 200 questionnaires based on Sekaran tables page 421. [5].

\section{B. Methods of Data Collection}

1) Data was collected through Questionnaire, we used none probability sampling techniques, specify convenience sampling technique this help us to find employees in their places such as workshops production lines and others yard ,also this methodology low cost and gain time.

2) All the respondents were questioned about the main factors causing the risk of the firm at the various areas such as satisfaction and performance in Giad Chemical Group Sudan. 
TABLE I

PSYCHOMETRIC PROPERTIES OF RISK MANAGEMENT.

\begin{tabular}{|c|c|c|c|c|c|c|}
\hline Independent Variables & $\mathrm{CR}$ & AVE & MSV & $\operatorname{Max} \mathrm{R}(\mathrm{H})$ & & \\
\hline Operational Risk & 0.918 & 0.693 & 0.721 & 0.926 & 0.832 & \\
\hline Strategic Risk & 0.821 & 0.697 & 0.667 & 0.832 & $0.817 * * *$ & \\
\hline Risk Control & 0.798 & 0.663 & 0.721 & 0.800 & $0.849 * * *$ & \\
\hline Change Risk & 0.777 & 0.636 & 0.661 & 0.795 & $0.807 * * *$ & 0.835 \\
\hline
\end{tabular}

TABLE II

Psychometric Properties of Industrial Firms Performance.

\begin{tabular}{|c|c|c|c|c|c|c|c|c|}
\hline Independent Variables & $\mathrm{CR}$ & AVE & MSV & $\operatorname{Max} \mathrm{R}(\mathrm{H})$ & & & & \\
\hline Customer Satisfaction & 0.774 & 0.634 & 0.672 & 0.815 & 0.796 & & & \\
\hline Community Result & 0.912 & 0.725 & 0.637 & 0.935 & 0.798 & 0.852 & & \\
\hline Main Result & 0.843 & 0.643 & 0.672 & 0.864 & 0.820 & 0.707 & 0.802 & \\
\hline Employee Satisfaction & 0.753 & 0.612 & 0.530 & 0.854 & 0.674 & 0.678 & 0.728 & 0.783 \\
\hline
\end{tabular}

TABLE III

Model Fit Indices And PATH CoEfFicients of Risk MANAgEMEnt ANd Firm .

\begin{tabular}{|c|c|c|c|c|c|}
\hline & Estimate & S.E. & C.R. & $\mathrm{P}$ & Result \\
\hline Community Result $\longleftarrow$ Operational Risk & 0.051 & 0.188 & 0.272 & 0.786 & Not support \\
\hline Community Result $\longleftarrow$ Strategic Risk & 0.326 & 0.167 & 1.953 & 0.051 & Not support \\
\hline Community Result $\longleftarrow$ Risk Control & 0.192 & 0.205 & 0.935 & 0.350 & Not support \\
\hline Community Result $\longleftarrow$ Change Risk & 0.44 & 0.214 & 2.058 & 0.040 & Support \\
\hline Main Result $\longleftarrow$ Operational Risk & 0.178 & 0.123 & 1.453 & 0.146 & Not support \\
\hline Main Result $\longleftarrow$ Strategic Risk & 0.066 & 0.106 & 0.618 & 0.537 & Not support \\
\hline Main Result $\longleftarrow$ Risk Control & 0.292 & 0.138 & 2.12 & 0.034 & Support \\
\hline Main Result $\longleftarrow$ Change Risk & 0.389 & 0.145 & 2.679 & 0.007 & Support \\
\hline Customer Satisfaction $\longleftarrow$ Operational Risk & 0.23 & 0.14 & 1.64 & 0.101 & Not support \\
\hline Customer Satisfaction $\longleftarrow$ Strategic Risk & 0.262 & 0.125 & 2.099 & 0.036 & Support \\
\hline Customer Satisfaction $\longleftarrow$ Risk Control & 0.148 & 0.152 & 0.973 & 0.330 & Not support \\
\hline Customer Satisfaction $\longleftarrow$ Change Risk & 0.062 & 0.151 & 0.411 & 0.681 & Not support \\
\hline Employee Satisfaction $\longleftarrow$ Operational Risk & 0.022 & 0.23 & 0.095 & 0.924 & Not support \\
\hline Employee Satisfaction $\longleftarrow$ Strategic Risk & 0.277 & 0.19 & 1.455 & 0.146 & Not support \\
\hline Employee Satisfaction $\longleftarrow$ Risk Control & 1.313 & 0.304 & 4.315 & $* * *$ & Support \\
\hline Employee Satisfaction $\longleftarrow$ Change Risk & 0.017 & 0.235 & 0.072 & 0.942 & Not support \\
\hline
\end{tabular}

\section{The Questionnaire}

A well-structured questionnaire consists of 3 sections: 1st section is the personnel informations which contain (5) questions; 2nd section is the risk management and it contains (20) questions; 3rd section is the firm performance and it contains (20) questions. The statements assessed by using a Likert scale of five-point scale ranging from 1 "strongly agree" to 5 "strongly dis agree".

\section{Management and Analysis of Data}

Data collected was analysed using the AMOS (Analysis of Moment Structures). Furthermore, the analysis and interpretation of data was done in diagrammatic form, tables, and graphs using frequencies and percentage analysis.

\section{REsults}

\section{A. Descriptive Statistics}

Assessment of descriptive statistics (Table 1: Psychometric Properties of Risk Management) reveals that all the variables fall within the predefined the important values.

\section{A Discussion of the Results}

Relationship between Risk Management (Multidimensional) and Firm Performance The relationship between risk management (Multi-dimensional) and firm performance, it is clear that from analysis the risk management has practical impact on firm performance, this is justified for many reasons, the main of them these firms dont adopted risk management systems, also the lack of training and awareness of risk management culture among employees and suitable tools use for risk management process. All these factors affected the relationship between risk management and firms performance in Giad Chemical Industrial Firms. Compare with other study we find the relationship between risk management and firm performance has positive impact. The result of regression analysis shows there is a positive and significant relationship between total risk management and company performance. Companies need to see risk management not only from defensive approach, but also as a key successes factor for sustainability of earnings and improvement in overall performance of the business. Effective risk management has direct implication on the earning performance of the company. 
The second hypothesis is also acceptable as the result shows positive outcome in performance in the companies which have higher investment in intellectual capital.

\section{CONCLUSions \& ReCOMmEndations}

1) The full board is responsible for overseeing the risk management structure, and for that purpose a list of key risk indicators (KRIs) should be developed and risks should be ranked and risk management should be including in firm structure.

2) Firm have to adopt more complex types of risk management.

3) Results show that the firms in chemical group presently have well defined strategies that are updated on a regular basis, they dont even take risk into account, they were not well defined and they were not translated well into organizational objectives at the operational level. there is no clear plan for risk management involving in firm strategy so a risk plan should be cascading from all department which including all step of risk process.

\section{REFERENCES}

[1] J. Abrhám and P. Lžičař, "Risk management in the sustainable development: Analysis of a selected key industry.," Journal of Security \& Sustainability Issues, vol. 8, no. 2, 2018.

[2] H. H. Al-Shibly, B. Louzi, and M. A. Hiassat, "The impact of risk management on construction projects success from the employees perspective," Interdisciplinary journal of contemporary research in business, vol. 5, no. 4, pp. 12-43, 2013.

[3] J. Sithipolvanichgul, "Enterprise risk management and firm performance: developing risk management measurement in accounting practice," 2016.

[4] I. S. V. Advisors, "Overview of the chemicals industry," tech. rep., 2007.

[5] E. Osipova, "Risk management in construction projects: a comparative study of the different procurement options in sweden," 2008.

[6] D.-W. Kwak, "Risk management in international container logistics operations: risk analysis and mitigating strategies," 2014.

[7] M. ROPEL and E. GAJEWSKA, "Risk management practices in a construction project-a case study," 2011. 
TABLE IV

LIST OF ABBREVIATIONS .

\begin{tabular}{|c|c|c|}
\hline No. & Abbreviation & Meaning \\
\hline 1 & PMBOK & Project Management Body of Knowledge \\
\hline 2 & ERM & Enterprise Risk Management \\
\hline 3 & IT & Information Technology \\
\hline 4 & PMI & Project Management Institute \\
\hline 5 & IEC & International Electro Technical Commission \\
\hline 6 & $\mathrm{RS}$ & Risk Score \\
\hline 7 & RPN & Risk Priority Number \\
\hline 8 & $\mathrm{RD}$ & Risk Design \\
\hline 9 & ERMS & Enterprise Risk Management System \\
\hline 10 & PMS & Performance Measurement System \\
\hline 11 & $\mathrm{ROA}$ & Return On Assets \\
\hline 12 & ROE & Return On Equity \\
\hline 13 & EPS & Earnings Per Share \\
\hline 14 & BIM & Building Information Modeling \\
\hline 15 & RMP & Risk Management Process \\
\hline 16 & ERP & Enterprise Resource Planning \\
\hline 17 & RBV & Resource-Based View \\
\hline 18 & IARC & Identification, Assessment, Response And Control \\
\hline 19 & ACSI & American Customer Satisfaction Index \\
\hline 20 & AMOS & Analysis of Moment Structure \\
\hline 21 & SEM & Structural Equation Model \\
\hline 22 & EFA & Exploratory Factor Analysis \\
\hline 23 & CFA & Confirmatory Factor Analysis \\
\hline 24 & SPSS & Statistical Package For The Social Sciences \\
\hline 25 & KMO & Kaiser-Meyer- Olkin \\
\hline 26 & TVE & Total Variance Explained \\
\hline 27 & MSA & Measure Of Sample Adequacy \\
\hline 28 & GFI & Goodness-of-Fit Index \\
\hline 29 & AGFI & Adjusted Goodness-of-Fit Index \\
\hline 30 & NFI & Normed Fit Index \\
\hline 31 & CFI & Comparative Fit Index \\
\hline 32 & RMR & Root Mean Square Residual \\
\hline 33 & RMSEA & Root Mean Square Error of Approximation \\
\hline 34 & SFL & Standardized Factor Loadings \\
\hline 35 & AVE & Average Variance Extracted \\
\hline 36 & $\mathrm{CR}$ & Composite Reliability \\
\hline 37 & CEO & Chief Executive Officer \\
\hline 38 & $\mathrm{COSO}$ & Committee of Sponsoring Firms of the Tread way Commission \\
\hline 39 & ISO & International Organization for Standardization \\
\hline 40 & $\mathrm{CRO}$ & Chief Risk Officer \\
\hline 41 & CFA & Confirmatory Factor Analysis \\
\hline 42 & C.R & Critical Ratio \\
\hline 43 & AVE & Average Variance Extracted \\
\hline 44 & $\mathrm{P}$ & Probability \\
\hline 45 & $\operatorname{Max}(\mathrm{R})$ & Regression \\
\hline 46 & S.E & Standard Error \\
\hline 47 & MSV & Maximum Share Variance \\
\hline
\end{tabular}

